\title{
A COMPREHENSIVE REVIEW ON ANALYTICAL PROFILE OF ANTI- DIABETIC DRUG
}

\section{GAYATRI DHOBALE ", PRIYA SAHANE, SURESH JADHAV, DUSHYANT GAIKWAD}

Pharmaceutical Quality Assurance, Vishal Institute of Pharmaceutical Education and Research, Ale, Tal. Junnar, Dist. Pune, Maharashtra, India

*Corresponding Author: Gayatri Dhobale; E Mail:: priyasahane146@gmail.com

Received $9^{\text {th }}$ May 2021; Revised 10 ${ }^{\text {th }}$ July 2021; Accepted $29^{\text {th }}$ Aug. 2021; Available online $15^{\text {th }}$ Dec. 2021

https://doi.org/10.31032/IJBPAS/2021/10.12.1030

\section{ABSTRACT}

Vildagliptin is an Oral Anti- Hyperglycaemic agent (antidiabetic drug) belonging to a new group of drugs called as dipeptidyl peptidase -4 inhibitor (DPP-4 inhibitor). Vildagliptin has been shown to reduce hyperglycaemia in type 2 Diabetes Mellitus. Vildagliptin inhibits the inactivation of GLP-1 and GIP by DPP-4, allowing GLP-1 and GIP to potentiate the secretion of insulin in the beta cells and suppress glucagon release by the alpha cells of the Islets of Langerhans in the pancreas \& reduces the blood sugar level. The present review assesses the various approaches for analysis of Vildagliptin in bulk drug as well as various formulations. A concise review represents the compilation and discussion of about more than 35 analytical methods which includes HPLC, UHPLC, LC-MS and UV-Spectrophotometry methods implemented for investigation of Vildagliptin in biological matrices, bulk samples and in different dosage formulations. This detailed review will be of great help to the researcher who is working on Vildagliptin.

Keywords : Vildagliptin; Analytical Profile; HPLC; HPTLC; UPLC; Bio-analytical;

Stability indicating

Abbreviations:

VLG: Vildagliptin 


\section{CAS: Chemical Abstracts Service pKa: Dissociation constant}

BCS: Biopharmaceutical Classification System

API: Active pharmaceutical ingredient

HPLC: High performance liquid chromatography

RP-HPLC: Reverse phase-high performance liquid Chromatography

RP-UHPLC: Reverse phase- Ultra high performance liquid Chromatography

LC-MS: Liquid chromatography-mass spectrometry

PDA: Photodiode array

ICH: International conference on harmonization RH: Relative Humidity tR: Retention time

LOD: Limit of Detection

LOQ: Limit of Quantitation

FDA: Food and Drug Administration

SIM: Stability indicating method

\section{INTRODUCTION}

Diabetes mellitus (DM) is probably one of the oldest diseases known to man. It was first reported in Egyptian manuscript about 3000 years ago [1]. In 1936, the distinction between type 1 and type 2 DM was clearly made [2]. Type $2 \mathrm{DM}$ was first described as a component of metabolic syndrome in 1988 [3]. Type 2 DM (formerly known as noninsulin dependent DM) is the most common form of DM characterized by hyperglycaemia, insulin resistance, and relative insulin deficiency [4]. Type 2 DM results from interaction between genetic, environmental and behavioural risk factors [5]. According to the International Diabetes Federation (IDF), approximately 415 million adults between the ages of 20 to 79 years had diabetes mellitus in 2015 [6]. In T2DM, the response to insulin is diminished, and this is defined as insulin resistance. During this state, insulin is ineffective and is initially countered by an increase in insulin production to maintain glucose homeostasis, but over time, insulin production decreases, resulting in T2DM. T2DM is most commonly seen in persons older than 45 years. Still, it is increasingly seen in children, adolescents, and younger adults due to rising levels of obesity, physical inactivity, and energy-dense diets [7].

Vildagliptin is an oral antihyperglycemic agent (ant diabetic drug) of the dipeptidyl peptidase4(DPP-4) inhibitor class of drug. Vildagliptin inhibits the inactivation of GLP1 and GIP by DPP-4 allowing GLP-1 and GIP to potentiate the secretion of insulin in 
the beta cells and suppress glucagon release by the alpha cells of the islets of Langerhans in the pancreas [8]. In investigative examination endeavor originate a novel reproducible and efficient HPLC technique with isocratic elution for assurance of vildagliptin in pharmaceutical formulation [9].

Table 1: Drug profile of Vildagliptin [10]

\begin{tabular}{|c|c|}
\hline Drug Name & Vildagliptin \\
\hline Structure & II \\
\hline Category & Oral Hypoglycaemic agent \\
\hline IUPAC name & $\begin{array}{c}\text { (2S)-1-\{2-[(3-hydroxyadamantan-1yl)amino]acetyl\}pyrrolidine-2 } \\
\text { carbonitrile }\end{array}$ \\
\hline Chemical Formula & C17H25N3O2 \\
\hline CAS no. & 274901-16-5 \\
\hline Molecular Mass & $303.3993 \mathrm{~g} / \mathrm{mole}$ \\
\hline Physical State & White to off white solid powder \\
\hline BCS class & I - High solubility and high bioavailability. \\
\hline Solubility & Soluble in Water and Methanol \\
\hline pKa & $14.71 \& 9.03$ Strongest acidic and basic respectively \\
\hline Absorption & $\begin{array}{c}\text { Rapidly absorbed following oral administration with an oral } \\
\text { bioavailability of greater than } 90 \% \text {. }\end{array}$ \\
\hline T1/2 & 90 minutes \\
\hline Therapeutic Use & Used to reduce hyperglycaemia in type 2 diabetes mellitus \\
\hline Storage & At room temperature between $68^{\circ} \mathrm{F}$ and $77^{\circ} \mathrm{F}\left(20^{\circ} \mathrm{C}\right.$ and $\left.25^{\circ} \mathrm{C}\right)$. \\
\hline
\end{tabular}

\section{Vildagliptin side effects:}

Some of the common and major side effects of Vildagliptin are:

- Headache

- Cough

- Constipation

- Dizziness
- Hypoglycaemia

- Weakness

- Excessive sweating

- Heartburn

- Swelling of face, lips and eyelids

- Upper respiratory tract infection 
Analytical techniques used for determination of Vildagliptin

\section{A. High-performance liquid chromatography} (HPLC):-

High Performance Liquid Chromatography is now one of the most powerful tools in analytical chemistry. It has the ability to separate, identify, and quantify the compounds that are present in any sample that can be dissolved in a liquid. High performance liquid chromatography (HPLC) is the most accurate analytical methods widely used for the quantitative as well as qualitative analysis of drug product [11].

Principle:-Solution of the sample is injected into a column of a porous material (stationary phase) and a liquid (mobile phase) is pumped at high pressure through the column. The separation of sample is based on the differences in the rates of migration through the column arising from different partition of the sample between the stationary and mobile phase.

Depending upon the partition behaviour of different components, elution at different time takes

Place [12].

Typical HPLC system consists of the following main components: [12]
1. Solvent Reservoirs:- Storage of sufficient amount of HPLC solvents for continuous operation of system.

In normal phase chromatography:

Mobile phase- Non polar

Stationary phase-polar

In reverse phase chromatography:

Mobile phase- Polar

Stationary phase- Non polar

Types of solvent delivery system: a) Isocratic elution:-Mobile phase composition is fixed.

b) Gradient elution:-Mobile phase composition is vary.

2. Pump: -This provides the constant and continuous flow of mobile phase through the system. Pumps can exert pressure up to 6000psi on mobile phase in HPLC. But for analytical work about 400-1500psi pressure is required. Pump can capable delivering $0.1-10 \mathrm{ml} / \mathrm{min}$ mobile phase flow rate. There are three types of pump used in HPLC:

I) Syringe/Displacement Pump

II) Reciprocating /Hydraulic Pump

III) Non-Reciprocating/Pneumatic Pump

3. Injector:-This allows an introduction of the analytes mixtures into the stream of the mobile phase before it enters the 
column. This system can be divided into two types:

I) Syringe injection:-a) Direct Injection on Column

b) Stop and Flow Injection

II) Loop and Valve System:-a) Fixed Loop and Valve System

b) Variable Volume Loop and Valve System

4. Column: - It is heart of HPLC system. It actually produces a separation of the analytes in a mixture. A column is place where mobile phase is in contact with stationary phase, forming an interface with enormous surface.

5. Detector: - The function of detector in HPLC is to monitor the mobile phase with or without the solute as it emerges from the column. Apperance of the analyte in the detector flow cell causes change of absorbance. If the analyte absorbs greater than background (mobile phase ) a positive signal is obtained e.g.: a) Refractive Index Detector

b) UV Detector-PDA c) Fluorescence Detector.

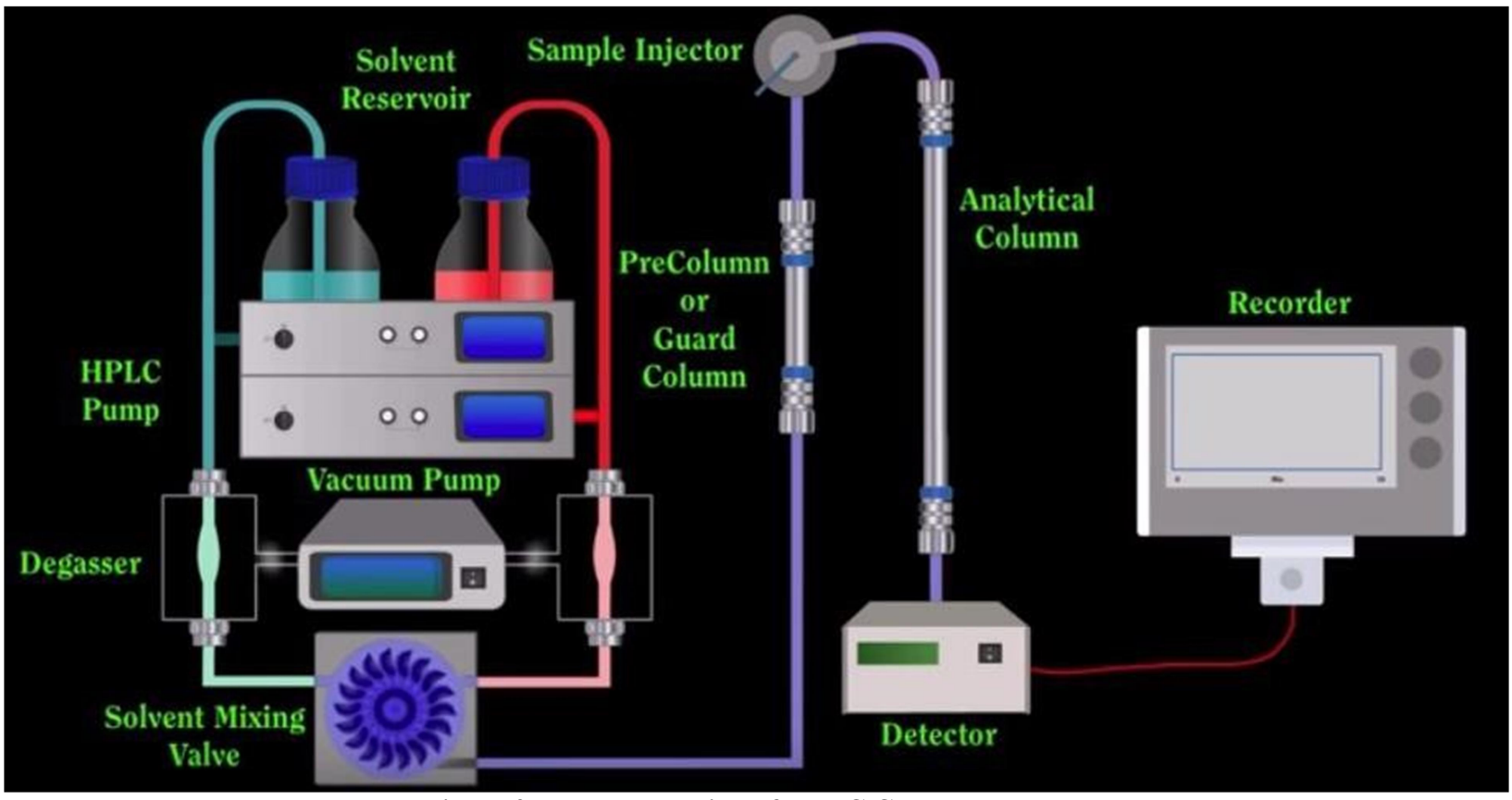

Figure 2: Instrumentation of HPLC Chromatography 


\begin{tabular}{|c|c|c|c|c|c|c|c|c|}
\hline $\begin{array}{l}\text { Sr. } \\
\text { No. }\end{array}$ & Drug & Method & $\begin{array}{c}\text { Stationary phase/ } \\
\text { Column }\end{array}$ & Mobile phase & Detection & $\begin{array}{l}\text { Linearity, } \\
\text { LOD } \\
\text { LOQ }\end{array}$ & $\begin{array}{l}\text { Retention } \\
\text { Time (min) \& } \\
\text { Flow rate } \\
\text { (ml } / \mathbf{m i n})\end{array}$ & Ref no. \\
\hline 1. & $\begin{array}{c}\text { Vildagli ptin } \\
\text { tablet }\end{array}$ & RP- HPLC & $\begin{array}{l}\text { Xterra }{ }^{\circledR} \text { waters } \\
\text { C18 column } \\
(150 \mathrm{~mm} \times 4 . \\
6 \mathrm{~mm}, 5 \mu \mathrm{m})\end{array}$ & $\begin{array}{r}25 \% \text { Ammonium } \\
\text { hydroxide+50\% } \\
\text { phosphoric acid } \\
\text { solution(pH9.5) : } \\
\text { Methanol } \\
(60: 40 \mathrm{v} / \mathrm{v})\end{array}$ & 210nm & $\begin{array}{l}\text { Linearity - } \\
5200 \mu \mathrm{g} / \mathrm{ml} \\
\text { LOD - } \\
1.47 \mu \mathrm{g} / \mathrm{ml} \\
\text { LOQ - } \\
4.90 \mu \mathrm{g} / \mathrm{ml}\end{array}$ & $\begin{array}{l}\text { Flow rate } 1 \mathrm{ml} / \mathrm{min} \\
\text { tR }-6.3 \mathrm{~min}\end{array}$ & [13] \\
\hline 2. & $\begin{array}{l}\text { Metform in } \\
\text { HCl \& }\end{array}$ & RPHPLC & $\begin{array}{l}\text { Dionex C18 } \\
(250 \mathrm{~mm} \\
4.6 \mathrm{~mm}, \text { id- }\end{array}$ & $\begin{array}{c}\text { 0.01M DiPotassium } \\
\text { hydrogen }\end{array}$ & 215nm & $\begin{array}{l}\text { MET: } \\
\text { Linearity - } \\
500-1500\end{array}$ & $\begin{array}{l}\text { Flow rate - } \\
1.5 \mathrm{ml} / \mathrm{min}\end{array}$ & [14] \\
\hline & $\begin{array}{l}\text { Vildagli ptin } \\
\text { tablet }\end{array}$ & & $5 \mu \mathrm{m}$ & $\begin{array}{l}\text { phosphate buffer: } \\
\text { Water }(90: 10 \mathrm{v} / \mathrm{v})\end{array}$ & & $\begin{array}{c}\mu \mathrm{g} / \mathrm{ml} \mathrm{LOD} \mathrm{-} \\
0.7057 \mu \mathrm{g} / \mathrm{ml} \\
\text { LOQ - } \\
2.3523 \mu \mathrm{g} / \mathrm{ml} \text { VLG : } \\
\text { Linearity - 50- } \\
150 \mu \mathrm{g} / \mathrm{ml} \\
\text { LOD - 0.6289 } \mu \mathrm{g} / \mathrm{ml} \\
\text { LOQ - } \\
2.0964 \mu \mathrm{g} / \mathrm{ml}\end{array}$ & tR - 2.39min & \\
\hline 3. & $\begin{array}{c}\text { Metform in } \\
\text { HCl } \\
\& \\
\text { Vildagli ptin } \\
\text { tablet }\end{array}$ & RPHPLC & $\begin{array}{c}\text { Phenomex } \\
\text { kromosil250mm } \times \\
4.6 \mathrm{~mm}, 5 \mu \mathrm{m}\end{array}$ & $\begin{array}{c}\text { 0.1M phosphate buffer } \\
\text { (pH6.8) : } \\
\text { Acetonitrile } \\
(75: 25 \mathrm{v} / \mathrm{v})\end{array}$ & $260 \mathrm{~nm}$ & 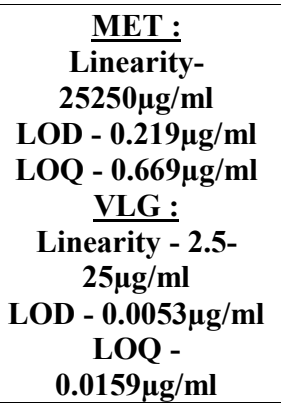 & $\begin{array}{l}\text { Flow rate } 1 \mathrm{ml} / \mathrm{min} \\
\text { tR -2.4min } \frac{\text { VLG : }}{\text { tR }-3.4 \mathrm{~min}}\end{array}$ & [15] \\
\hline 4. & $\begin{array}{l}\text { Vildagli ptin } \\
\text { tablet }\end{array}$ & RPHPLC & $\begin{array}{c}\text { Phenomex C18 } \\
\text { column } \\
(5 \mu \mathrm{m}, \\
250 \mathrm{~mm} \times \\
4.6 \mathrm{~mm})\end{array}$ & $\begin{array}{c}\text { Methanol: water (60:40 } \\
\text { v/v) pH } 4.5 \text { adjusted with } \\
\text { OPA }\end{array}$ & $207 \mathrm{~nm}$ & $\begin{array}{c}\text { Linearity- } \\
1060 \mu \mathrm{g} / \mathrm{ml} \\
\text { LOD - } \\
0.98 \mu \mathrm{g} / \mathrm{ml} \\
\text { LOQ - } \\
2.98 \mu \mathrm{g} / \mathrm{ml}\end{array}$ & $\begin{array}{l}\text { Flow rate- } \\
0.8 \mathrm{ml} / \mathrm{min} \\
\text { tR }-3.58 \mathrm{~min}\end{array}$ & [16] \\
\hline
\end{tabular}




\begin{tabular}{|c|c|c|c|c|c|c|c|c|}
\hline 5. & $\begin{array}{l}\text { Metform in } \\
\text { HCI \&Vildag } \\
\text { liptin tablet }\end{array}$ & $\begin{array}{c}\text { RP- } \\
\text { HPLC }\end{array}$ & $\begin{array}{l}\text { Xterra C18 } \\
\text { column } \\
(250 \mathrm{~mm} \times 4 . \\
6 \mathrm{~mm} \mathrm{I.D} \times \\
5 \mu)\end{array}$ & 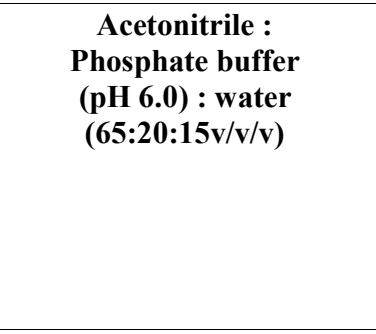 & 239nm & 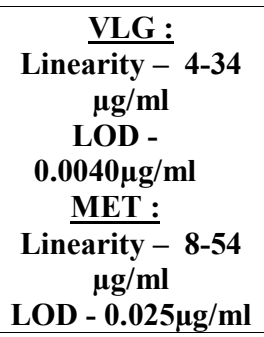 & $\begin{array}{l}\text { Flow rate1 } \mathrm{ml} / \mathrm{min} \\
\begin{array}{c}\text { VLG : } \\
\text { tR }-2.32 \mathrm{~min}\end{array} \\
\text { tR } \frac{\text { MET : }}{-4.29 \mathrm{~min}}\end{array}$ & [17] \\
\hline 6. & $\begin{array}{l}\text { Metform in } \\
\text { HCl \&Vildag } \\
\text { liptin }\end{array}$ & $\begin{array}{c}\text { RP- } \\
\text { HPLC }\end{array}$ & $\begin{array}{c}\text { Chromosil } \\
\text { ODS C18 } \\
\text { column }(250 \mathrm{x}\end{array}$ & $\begin{array}{c}\text { 0.1M DiPotassium } \\
\text { hydrogen phosphate : } \\
\text { Methanol }\end{array}$ & 258nm & 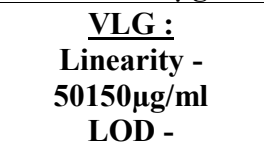 & $\begin{array}{l}\text { Flow rate- } \\
0.5 \mathrm{ml} / \mathrm{min} \\
\text { MET : }\end{array}$ & [18] \\
\hline & tablet & & $4.6 \mathrm{~mm} 5 \mu)$ & $\begin{array}{c}\text { (60:40\%v/v) adjust } \mathrm{pH}- \\
9.2 \text { by using Ortho } \\
\text { phosphoric } \\
\text { acid }\end{array}$ & & $\begin{array}{c}0.0015 \mu \mathrm{g} / \mathrm{ml} \\
\text { LOQ - } \\
0.0043 \mu \mathrm{g} / \mathrm{ml} \\
\text { MET: } \\
\text { Linearity - } \\
\text { LOD - } \\
0.005 \mu \mathrm{g} / \mathrm{ml} \\
\text { LOQ - } \\
0.014 \mu \mathrm{g} / \mathrm{ml}\end{array}$ & $\begin{array}{l}\text { tR- 1.43min } \\
t R \frac{V L G:}{-5.32 \mathrm{~min}}\end{array}$ & \\
\hline 7. & $\begin{array}{c}\text { Vildagli ptin } \\
\text { Tablet }\end{array}$ & $\begin{array}{c}\text { RP- } \\
\text { HPLC }\end{array}$ & $\begin{array}{c}\text { Qualisil } \\
\text { BDS C18 } \\
\text { column }(250 \times \\
4.6 \mathrm{~mm}, 5 \mu)\end{array}$ & $\begin{array}{c}\text { 0.1M DiPotassium } \\
\text { hydrogen phosphate } \\
\text { buffer : Acetonitrile } \\
(70: 30 \% \text { /v) adjust pH-7 } \\
\text { by using O- phosphoric } \\
\text { acid }\end{array}$ & $263 \mathrm{~nm}$ & $\begin{array}{c}\text { Linearity - } \\
1060 \mu \mathrm{g} / \mathrm{ml} \\
\text { LOD - } \\
0.45 \mu \mathrm{g} / \mathrm{ml} \\
\mathrm{LOQ}- \\
0.98 \mu \mathrm{g} / \mathrm{ml}\end{array}$ & $\begin{array}{l}\text { Flow rate- } \\
0.5 \mathrm{ml} / \mathrm{min}\end{array}$ & [19] \\
\hline 8. & $\begin{array}{l}\text { Metform in } \\
\text { HCl \& Vildag } \\
\text { liptin tablet }\end{array}$ & RP- HPLC & $\begin{array}{c}\text { ZODIAC C18 } \\
\text { column }(250 \times \\
4.6 \mathrm{~mm}, 5 \mu)\end{array}$ & $\begin{array}{c}\text { Disodium Hydrogen } \\
\text { phosphate buffer(pH3.5): } \\
\text { Methanol } \\
(73.5: 26.5 \mathrm{v} / \mathrm{v})\end{array}$ & 200nm & $\begin{array}{c}\text { MET: } \\
\text { Linearity - } \\
75175 \mu \mathrm{g} / \mathrm{ml} \\
\text { LOD - 0.09ppm } \\
\text { LOQ - 0.28ppm } \\
\text { VLG : } \\
\text { Linearity - } \\
7.5-17.5 \mu \mathrm{g} / \mathrm{ml} \\
\text { LOD - 0.38ppm } \\
\text { LOQ } \\
-1.15 \mathrm{ppm}\end{array}$ & $\begin{array}{l}\text { Flow rate1 ml/min } \\
\frac{\text { MET : tR- }}{2.490 \mathrm{~min}} \\
\text { tR }-\frac{\text { VLG : }}{4.243} \mathrm{~min}\end{array}$ & [20] \\
\hline
\end{tabular}




\begin{tabular}{|c|c|c|c|c|c|c|c|c|}
\hline 9. & $\begin{array}{l}\text { Metform in } \\
\text { HCl \&Vildag } \\
\text { liptin tablet }\end{array}$ & RP- HPLC & $\begin{array}{c}\text { Water's C18 } \\
\text { column }(150 x \\
4.6 \mathrm{~mm}, 5 \mu)\end{array}$ & $\begin{array}{c}\text { 0.1M DiPotassium } \\
\text { phosphate buffer : } \\
\text { Acetonitrile } \\
(\mathbf{7 0 : 3 0 \% v / v )}\end{array}$ & 258nm & $\begin{array}{c}\text { MET : } \\
\text { Linearity - } \\
1000-3000 \\
\mu \mathrm{g} / \mathrm{ml} \text { LOD - } \\
1.1 \mathrm{ng} / \mathrm{ml} \\
\text { LOQ - 3.6ng/ml } \\
\text { VLG : } \\
\text { Linearity - } \\
100-300 \mu \mathrm{mg} / \mathrm{ml} \\
\text { LOD - 0.3ng/ml } \\
\text { LOQ - 0.8ng/ml }\end{array}$ & $\begin{array}{l}\text { Flow rate1 ml/min } \\
\begin{array}{c}\text { MET : } \\
\text { tR -1.4min } \\
\text { tR - } \frac{\text { VLG : }}{5.3 \mathrm{~min}}\end{array}\end{array}$ & [21] \\
\hline
\end{tabular}

\begin{tabular}{|c|c|c|c|c|c|c|c|c|}
\hline 10. & $\begin{array}{c}\text { Metform in } \\
\text { HCl } \\
\text { \&Vildag } \\
\text { liptin tablet }\end{array}$ & RP- HPLC & $\begin{array}{l}\text { Lichrocart } \\
\text { C18column } \\
(250 \mathrm{~mm} x \\
4.6 \mathrm{~mm}, 5 \mu)\end{array}$ & $\begin{array}{r}\text { 0.05M KH2PO4 : } \\
\text { Acetonitrile } \\
(70: 30 \% v / v)\end{array}$ & $215 \mathrm{~nm}$ & 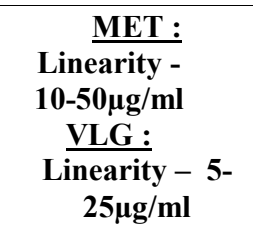 & $\begin{array}{l}\text { Flow rate } 1 \mathrm{ml} / \mathrm{min} \\
\text { MET : tR - } \\
\text { 5.18min VLG : } \\
\text { tR- } 6.64 \mathrm{~min}\end{array}$ & {$[22]$} \\
\hline 11. & $\begin{array}{c}\text { Vildagli } \\
\text { ptin tablet }\end{array}$ & $\begin{array}{c}\text { RP- } \\
\text { HPLC }\end{array}$ & $\begin{array}{c}\text { X-bridge C18 } \\
\text { column }\end{array}$ & $\begin{array}{c}\text { Phosphate buffer } \\
\text { pH6.8 : Acetonitrile } \\
(67: 33 \mathrm{v} / \mathrm{v})\end{array}$ & 239nm & - & Flow rate $1 \mathrm{ml} / \mathrm{min}$ & [23] \\
\hline 12. & $\begin{array}{l}\text { Metform in } \\
\text { \& Vildagli } \\
\text { ptin tablet }\end{array}$ & $\begin{array}{c}\text { RP- } \\
\text { HPLC }\end{array}$ & $\begin{array}{l}\text { Thermo } \\
\text { Hypersil } \\
\text { ODS C18 } \\
(250 \mathrm{~mm} x \\
4.6 \mathrm{~mm}, 5 \mu)\end{array}$ & $\begin{array}{c}\text { 0.1M Potassium } \\
\text { Hydrogen phosphate } \\
\text { buffer pH7 : } \\
\text { Acetonitrile } \\
(60: 40 \mathrm{v} / \mathrm{v})\end{array}$ & $263 \mathrm{~nm}$ & - & $\begin{array}{l}\text { Flow rate1 ml/min } \\
\text { MET : tR - } \\
\begin{array}{c}2.1 \mathrm{~min} \underline{\text { VLG }} \\
\vdots \\
\mathrm{tR}-3.5 \mathrm{~min}\end{array}\end{array}$ & [24] \\
\hline 13. & $\begin{array}{c}\text { Vildagli } \\
\text { ptin tablet }\end{array}$ & $\begin{array}{c}\text { RP- } \\
\text { HPLC }\end{array}$ & $\begin{array}{c}\text { Agilent eclipse } \\
\text { XDB C18 } \\
\text { column }(150 \\
\text { mm x } \\
4.6 \mathrm{~mm}, 5 \mu)\end{array}$ & $\begin{array}{c}\text { 0.1M phosphate buffer } \\
\text { (pH6.8) : } \\
\text { Acetonitrile } \\
(85: 15 v / v)\end{array}$ & $210 \mathrm{~nm}$ & $\begin{array}{c}\text { Linearity - } \\
10150 \mu \mathrm{g} / \mathrm{ml} \\
\text { LOD - } \\
0.0329 \mu \mathrm{g} / \mathrm{ml} \\
\mathrm{LOQ}- \\
0.0998 \mu \mathrm{g} / \mathrm{ml}\end{array}$ & $\begin{array}{c}\text { Flow rate } 1 \mathrm{ml} / \mathrm{min} \\
\text { tR-3.04min }\end{array}$ & [25] \\
\hline 14. & $\begin{array}{c}\text { Vildagli } \\
\text { ptin tablet }\end{array}$ & $\begin{array}{c}\text { RP- } \\
\text { HPLC }\end{array}$ & $\begin{array}{c}\text { Thermosil C18 } \\
\text { column }(4.6 \mathrm{x} \\
150 \mathrm{~mm}, \\
5 \mu \mathrm{m})\end{array}$ & $\begin{array}{c}\text { pH 8.2Buffer : } \\
\text { Acetonitrile: } \\
\text { Methanol } \\
\text { (450: } 480: 70 \mathrm{v} / \mathrm{v})\end{array}$ & $254 \mathrm{~nm}$ & $\begin{array}{c}\text { Linearity 50-90 } \\
\mu \mathrm{g} / \mathrm{ml} \text { LOD - } \\
2.98 \mathrm{~g} / \mathrm{ml} \\
\text { LOQ }-9.94 \mathrm{~g} / \mathrm{ml} \\
\end{array}$ & $\begin{array}{c}\text { Flow rate- } 0.5 \mathrm{ml} / \\
\text { min } \\
\text { tR }-\mathbf{3 . 9 0 6} \text { min }\end{array}$ & [26] \\
\hline 15. & $\begin{array}{c}\text { Vildagli } \\
\text { ptin tablet }\end{array}$ & $\begin{array}{c}\text { RP - } \\
\text { HPLC }\end{array}$ & $\begin{array}{l}\text { Altima C18 } \\
\text { column (150 } \\
\end{array}$ & $\begin{array}{c}\text { pH } 2.6 \text { buffer : } \\
\text { Acetonitrile }(72: 28 \mathrm{v} / \mathrm{v})\end{array}$ & $266 \mathrm{~nm}$ & $\begin{array}{l}\text { Linearity - } \\
\text { LOD - } 0.06\end{array}$ & $\begin{array}{c}\text { Flow rate-1 } \\
\mathrm{ml} / \mathrm{min}\end{array}$ & [27] \\
\hline
\end{tabular}




\begin{tabular}{|c|c|c|c|c|c|c|c|c|}
\hline & & & $\begin{array}{c}\mathrm{mm} x \\
4.6 \mathrm{~mm}, 5 \mu \mathrm{m})\end{array}$ & & & $\begin{array}{c}\mu \mathrm{g} / \mathrm{ml} \mathrm{LOQ}- \\
0.21 \mu \mathrm{g} / \mathrm{ml}\end{array}$ & tR- $3.25 \mathrm{~min}$ & \\
\hline 16. & $\begin{array}{c}\text { Vildagli } \\
\text { ptin tablet }\end{array}$ & $\begin{array}{c}\text { RP - } \\
\text { HPLC }\end{array}$ & $\begin{array}{c}\text { ShimpackVP- } \\
\text { ODScolumn(150 } \\
\text { mm x } 4.66 \mathrm{~mm} \text {, } \\
5 \mu \mathrm{m})\end{array}$ & $\begin{array}{c}\text { 0.02 M Phosphate } \\
\text { buffer pH 4.6 : } \\
\text { Acetonitrile } \\
(80: 20 \mathrm{v} / \mathrm{v}) \\
\end{array}$ & $\begin{array}{c}\text { PDA } \\
\text { detector } \\
210 \mathrm{~nm}\end{array}$ & $\begin{array}{c}\text { Linearity - } \\
20-70 \mu \mathrm{g} / \mathrm{ml}\end{array}$ & Flow rate-1 $\mathrm{ml} / \mathrm{min}$ & [28] \\
\hline 17. & $\begin{array}{c}\text { Metform in } \\
\text { \& Vildagli } \\
\text { ptin } \\
\text { Bulk, } \\
\text { Tablet }\end{array}$ & $\begin{array}{c}\text { RP- } \\
\text { UHPLC }\end{array}$ & $\begin{array}{c}\text { Agilent } \\
\text { Zorbax } \\
\text { Eclipse Plus } \\
\text { C18 column } \\
(150 \mathrm{~mm} x \\
4.66 \mathrm{~mm}, 5 \mu \mathrm{m})\end{array}$ & $\begin{array}{c}\text { Acetonitrile : } \\
\text { Potassium } \\
\text { dihydrogen } \\
\text { phosphate buffer } \\
(\text { pH4.2) : } \\
(80: 20 \mathrm{v} / \mathrm{v})\end{array}$ & $\begin{array}{c}\text { DAD } \\
\text { detection- } \\
207 \mathrm{~nm}\end{array}$ & $\begin{array}{c}\text { MET : } \\
\text { Linearity - 20-100 } \\
\mu \mathrm{g} / \mathrm{ml} \\
\text { LOD - } \\
1.74 \mu \mathrm{g} / \mathrm{ml} \mathrm{LOQ} \mathrm{-} \\
5.79 \mu \mathrm{g} / \mathrm{ml} \\
\\
\text { VLG : } \\
\text { Linearity - 20- } \\
100 \mu \mathrm{g} / \mathrm{ml} \mathrm{LOD} \\
- \\
2.20 \mu \mathrm{ml} / \mathrm{mOQ}- \\
7.33 \mu \mathrm{g} / \mathrm{ml} \\
\end{array}$ & $\begin{array}{c}\text { Flow } \\
\text { rate0.6ml/min } \\
\text { MET : } \\
\text { tR-2.5min } \\
\text { VLG: } \\
\text { tR-3.67min }\end{array}$ & [29] \\
\hline 18. & $\begin{array}{l}\text { Metform in } \\
\text { HCL \& } \\
\text { Vildagli } \\
\text { ptin } \\
\text { Bulk, } \\
\text { Tablet }\end{array}$ & $\begin{array}{l}\text { RP - } \\
\text { HPLC }\end{array}$ & $\begin{array}{c}\text { BDS } \\
\text { HYPERSIL } \\
\text { C18 column } \\
(4.6 \mathrm{~mm} \\
\times 250 \mathrm{~mm})\end{array}$ & $\begin{array}{c}50 \mathrm{mM} \\
\text { phosphate buffer } \\
\text { (pH 6): Methanol } \\
\text { : Acetonitrile } \\
(50: 30: 20 \mathrm{v} / \mathrm{v})\end{array}$ & $220 \mathrm{~nm}$ & $\begin{array}{c}\text { Linearity - 10- } \\
60 \mu \mathrm{g} / \mathrm{ml} \text { MET } \\
\dot{\bar{L}} \mathrm{LOD}-1.09 \\
\mu \mathrm{g} / \mathrm{ml} \text { LOQ - } \\
3.32 \\
\mu \mathrm{g} / \mathrm{ml} \\
\\
\text { VLD : LOD- } \\
1.70 \mu \mathrm{g} / \mathrm{ml} \\
\text { LOQ- 5.15 } \\
\mu \mathrm{g} / \mathrm{ml}\end{array}$ & $\begin{array}{c}\text { Flow rate } \\
\text { 0.8ml/min. } \\
\text { MET : } \\
\text { tR-3.7min } \\
\\
\text { VLG: } \\
\text { tR-4.8min }\end{array}$ & [30] \\
\hline 19. & $\begin{array}{c}\text { Metform in } \\
\text { \& Vildagli } \\
\text { ptin } \\
\text { Bulk, } \\
\text { Tablet }\end{array}$ & $\begin{array}{c}\text { RP - } \\
\text { HPLC }\end{array}$ & $\begin{array}{c}\text { ODS } \\
\text { column(4.6× } \\
250 \mathrm{~mm}, \\
5 \mu \mathrm{m}, \\
\text { Hypersil) }\end{array}$ & $\begin{array}{c}\text { ACN: Methanol: } \\
\text { Water } \\
(15: 60: 25 \mathrm{v} / \mathrm{v})\end{array}$ & $278 \mathrm{~nm}$ & $\begin{array}{c}\text { Linearity - } \\
1-5 \mu \mathrm{g} / \mathrm{ml} \text { MET: } \\
\text { LOD- } \\
0.617 \mu \mathrm{g} / \mathrm{ml} \mathrm{LOQ-} \\
1.87 \\
\mu \mathrm{g} / \mathrm{ml} \\
\\
\text { VLD : } \\
\text { LOD- } \\
0.154 \mu \mathrm{g} / \mathrm{ml} \mathrm{LOQ-} \\
0.468 \mu \mathrm{g} / \mathrm{ml} \\
\end{array}$ & $\begin{array}{c}\text { Flow rate } \\
0.8 \mathrm{ml} / \mathrm{min} \text {. }\end{array}$ & [31] \\
\hline
\end{tabular}


B. UV- visible spectrophotometric method: [32]

UV - VIS spectrometry concerns with the consequences of electromagnetic radiation in the $\mathrm{UV}$ and/or Visible region with the absorbing species like atoms, molecules or ions. UV-VIS spectroscopy is type of absorption \& molecular spectroscopy. UV radiations lie between $200-400 \mathrm{~nm}$ while visible radiations lies in between $400800 \mathrm{~nm}$ wavelength region.

Principle: - when UV-VIS radiations are incident on substance, then it interacted with molecule which absorbs these radiations \& its electron goes from ground state to excited state by changing their electronic transition. In which wavelength \& frequency of absorption is measured for qualitative \& quantitative analysis respectively.

Absorption of UV-VIS radiation is directly proportional to $\operatorname{conc}^{\mathrm{n}}$ of substance (Beers law) \& thickness of medium (Lamberts law).

Typical UV-VIS spectrometry consists of the following main components:
1) Source: It is used to emit UV-VIS radiations. e.g.- Tungsten Source, Hydrogen discharge lamp, Deuterium lamp, Xenon discharge lamp, Mercury arc lamp.

2) Monochromators: These are used to select single wavelength radiations \& block others. The essential elements are -

i) Entrance Slit- It allows UV-VIS radiations to incident on dispersing element.

ii) Dispersing element - Specific wavelength radiations can be selected. These are of 2 types:
a) Prism
b) Grating
iii) Exit slit - It allows nominal wavelength together with a band of wavelength on either side selected by dispersing element.
3) Sample Holder/Cuvette:- Sample cells that are to be contains sample for analysis

4) Detectors:- These are used to detect intensity of UV radiations falls on it. There are three types of detectors:
a) Photo voltaic cell/Barrier layer cell
b) Photo cell / Photo tube
c) Photo multiplier tube 


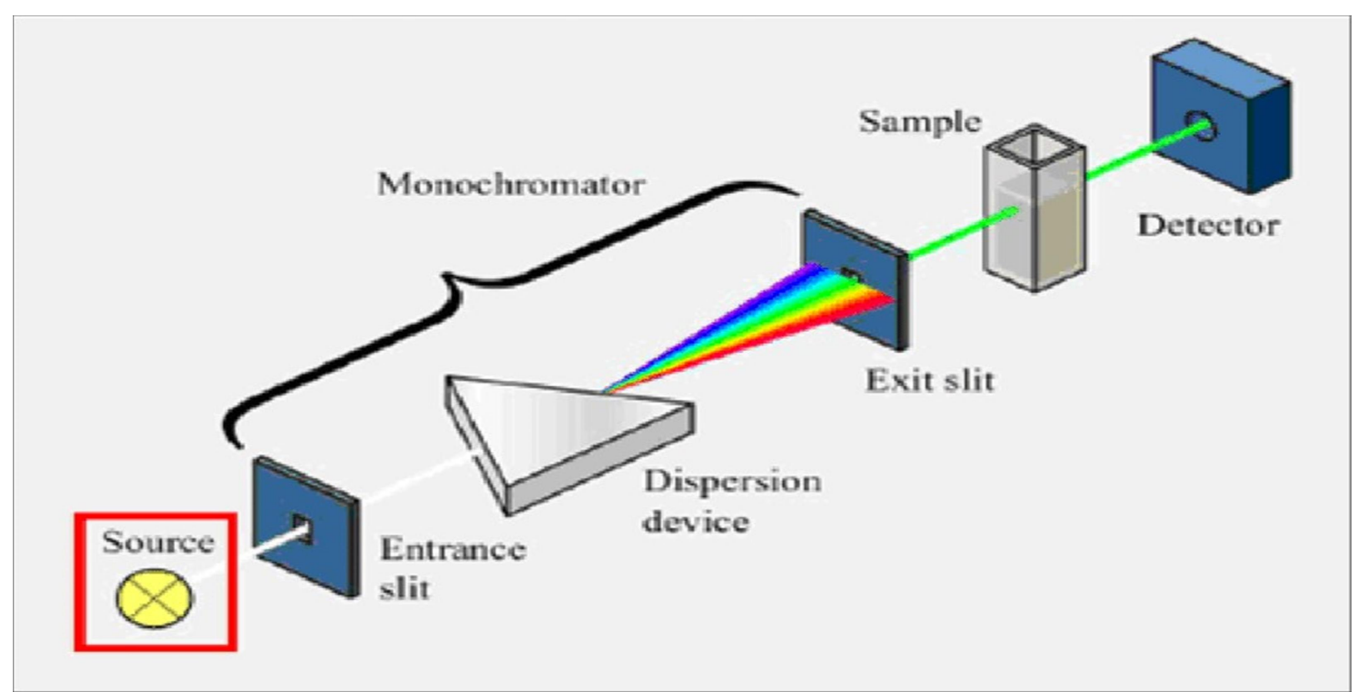

Figure 1: Single beam UV-Visible Spectrometer

Table 3: UV method for Vildagliptin

\begin{tabular}{|c|c|c|c|c|c|c|c|}
\hline $\begin{array}{l}\text { Sr. } \\
\text { No. }\end{array}$ & Drug & Matrix & Method & Solvent & Detectio n & $\begin{array}{c}\text { Linearity, LOD, } \\
\text { LOQ }\end{array}$ & Ref. No. \\
\hline 1. & $\begin{array}{l}\text { Vildagliptin } \\
\text { tablet }\end{array}$ & Bulk & $\begin{array}{c}\text { UV visible } 1601 \\
\text { Shimadzu double beam } \\
\text { spectrophotometer }\end{array}$ & Water & $244 \mathrm{~nm}$ & $\begin{array}{c}\text { Linearity - 12.5-200 } \\
\mu \mathrm{g} / \mathrm{ml} \text { LOD - } \\
\text { LOQ - }\end{array}$ & [33] \\
\hline 2. & $\begin{array}{c}\text { Vildagliptin } \\
\text { tablet }\end{array}$ & $\begin{array}{l}\text { Bulk, } \\
\text { Tablet }\end{array}$ & $\begin{array}{c}\text { UV-VIS } \\
\text { spectrophotometer } \\
\text { (Shimadzu model } \\
18001) \\
\end{array}$ & $\begin{array}{l}0.5 \mathrm{M} \\
\text { HCL }\end{array}$ & $202.5 \mathrm{~nm}$ & $\begin{array}{c}\text { Linearity - 10-35 } \mu \mathrm{g} / \mathrm{ml} \\
\text { LOD }-0.055 \mu \mathrm{g} / \mathrm{ml} \\
\text { LOQ }-0.166 \mu \mathrm{g} / \mathrm{ml}\end{array}$ & [34] \\
\hline 3. & $\begin{array}{l}\text { Vildagliptin } \\
\text { \& } \\
\text { Metformin } \\
\text { HCL }\end{array}$ & Bulk, Tablet & $\begin{array}{c}\text { LABINDIA } \\
\text { spectrophotometer }\end{array}$ & Water & $\begin{array}{l}\frac{\text { VLG 217 }}{\mathrm{nm}} \\
\frac{\text { MET -234 }}{\mathrm{nm}}\end{array}$ & $\begin{array}{c}\text { VLG : } \\
\text { Linearity }-0.7 \mu \mathrm{g} / \mathrm{ml} \\
\text { LOD -0.074 } \mu \mathrm{g} / \mathrm{ml} \text { LOQ - } \\
0.225 \mu \mathrm{g} / \mathrm{ml} \text { MET : } \\
\text { Linearity }-7 \mu \mathrm{g} / \mathrm{ml} \\
\text { LOD }-0.44 \mu \mathrm{g} / \mathrm{ml} \\
\text { LOQ }-1.35 \mu \mathrm{g} / \mathrm{ml}\end{array}$ & [35] \\
\hline 4. & Vildagliptin & Bulk, Tablet & $\begin{array}{l}\text { UV-Visible double beam } \\
\text { spectrophotometer }\end{array}$ & $\begin{array}{l}0.1 \mathrm{~N} \\
\text { HCL }\end{array}$ & $210 \mathrm{~nm}$ & $\begin{array}{c}\text { Linearity }-5-60 \mu \mathrm{g} / \mathrm{ml} \\
\text { LOD }-0.951 \mu \mathrm{g} / \mathrm{ml} \\
\text { LOQ }-2.513 \mu \mathrm{g} / \mathrm{ml}\end{array}$ & [36] \\
\hline 5. & Vildagliptin & $\begin{array}{l}\text { Bulk, } \\
\text { Tablet }\end{array}$ & $\begin{array}{c}\text { Schimadzu } 1800 \text { version } \\
1.12- \\
\text { Double Beam UV- } \\
\text { Visible } \\
\text { spectrophotometer } \\
\end{array}$ & $0.1 \mathrm{~N} \mathrm{NaOH}$ & $216 \mathrm{~nm}$ & $\begin{array}{l}\text { Linearity - 10-100 } \\
\mu \mathrm{g} / \mathrm{ml} \text { LOD - } \\
\text { LOQ - }\end{array}$ & [37] \\
\hline 6. & $\begin{array}{c}\text { Vildagliptin } \\
\& \\
\text { Linagliptin }\end{array}$ & Bulk, Tablet & $\begin{array}{c}\text { UV-Visible } \\
\text { spectrophotometer } \\
\text { (Shimadzu UV1800 ) }\end{array}$ & $\begin{array}{c}\text { VLG - } \\
\text { Distilled } \\
\text { water } \\
\frac{\text { LNG - }}{\text { Methanol }}\end{array}$ & $\begin{array}{l}\frac{\text { VLG }-197}{\mathrm{~nm}} \\
\frac{\mathrm{LNG}-294}{\mathrm{~nm}}\end{array}$ & 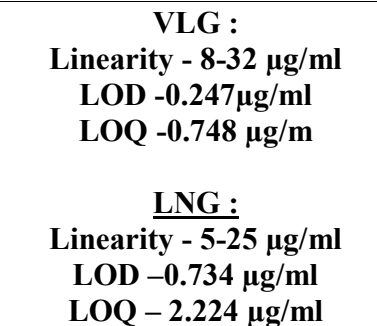 & [38] \\
\hline 7. & $\begin{array}{c}\text { Vildagliptin } \\
\& \\
\text { Metformin }\end{array}$ & Bulk, Tablet & $\begin{array}{c}\text { Double beam } \\
\text { spectrophotometer } \\
\text { (Shimadzu UV-VIS } \\
\text { 1700) }\end{array}$ & $0.1 \mathrm{~N} \mathrm{NaOH}$ & $\begin{array}{l}\frac{\text { VLG - }}{233 \mathrm{~nm}} \\
\frac{\text { MET }}{216 \mathrm{~nm}}\end{array}$ & $\begin{array}{c}\text { VLG : } \\
\text { Linearity - 30-70 } \\
\mu \mathrm{g} / \mathrm{ml} \text { MET : } \\
\text { Linearity }-5-25 \mu \mathrm{g} / \mathrm{ml}\end{array}$ & [39] \\
\hline
\end{tabular}




\section{Stability Indicating Method:}

Singh and Bakshi discussed some conclusive points of developing SIM. Dolan suggests the comments on SIA. Smela discussed regulatory points about SIM is analytical method.

A Stability-indicating assay method can be defined as "Validated quantitative analytical method that can detect the change with time in the chemical, physical or microbiological properties of the drug substance and drug products are specific so that the content of active ingredients and degradation products can be accurately measured without interference" [40].

Generally forced degradation/stress testing is used to generate the samples for stabilityindicating assay methods. Forced degradation/stress testing is defined as "the stability testing of drug substance and drug product under conditions exceeding those used for accelerated stability testing" [41].

Degradation can be achieved by exposing the drug, for extended period of time, to extremes of $\mathrm{pH}(\mathrm{HCl}$ or $\mathrm{NaOH}$ solutions of different strengths), at elevated temperature, to hydrogen peroxide at room temperature, to UV light, and to dry heat (in an oven) to achieve degradation to an extent of 5-20\% [42].
According to FDA guidelines (Guidance for Industry, Analytical Procedures and Methods Validation, FDA, 2000), a Stability Indicating Method (SIM) is defined as a validated analytical peptide testing procedure that accurately and precisely measure active ingredients (drug substance or drug product) free from process impurities, excipients and degradation products [43].

SIM procedure is used to measure the diminution the quantity of API in drug substances prefer degradation Studies. SIM may also check stability of drug matter and Products changes in separate time intervals of study. These method accurately estimate the changes API concentrations .In the absence of impurities, excipients and other degradation products. Stress testing is done to demonstrate specificity of the created method to quantify the adjustments in grouping of substance when little data is accessible about prospective degradation product. The improvement of reasonable Stability indicating method provides a background for preformulation thinks about, stability examines and improve the proper storage condition [44]. These ICH guidelines are relevant to forced degradation Study:

- ICH Q1A: Stability testing of New Drug Substance and Products. 
- ICH Q1B: Photo stability testing of New Drug Substance and Products.

- ICH Q1C : Stability testing of New Dosage Forms

- ICH Q1D : Bracketing and Matrixing Designs for stability testing of Drug Substances and Products

- ICH Q1E : Evaluation of stability data

- ICH Q1F : Stability data package for Registration Applications in Climatic Zones III and IV
- ICH Q2B: Validation of analytical procedure, methodology.

- ICH Q5C : Stability testing of Biotechnological/Biological Products Solution state stability :

1. Acidic hydrolysis

2. Alkaline hydrolysis

3. Hydrolytic

4. Oxidative degradation Solid state solubility:

1. Thermal degradation

2. Photolytic degradation

Table 4: Types of Stability Studies

\begin{tabular}{|c|c|c|}
\hline Study Type & Storage condition & $\begin{array}{c}\text { Minimum time period covered by data at } \\
\text { submission }\end{array}$ \\
\hline Long Term & $25^{\circ} \mathrm{C} \pm 2^{\circ} \mathrm{C}$ and $60 \%$ RH $\pm 5 \%$ RH or & 12 months \\
& $30^{\circ} \mathrm{C} \pm 2^{\circ} \mathrm{C}$ and $65 \% \mathrm{RH} \pm 5 \%$ RH & 6 months \\
\hline Intermediate & $30^{\circ} \mathrm{C} \pm 2^{\circ} \mathrm{C}$ and $65 \% \mathrm{RH} \pm 5 \%$ RH & 6 months \\
\hline Accelerated & $40^{\circ} \mathrm{C} \pm 2^{\circ} \mathrm{C}$ and $75 \% \mathrm{RH} \pm 5 \%$ RH & \\
\hline
\end{tabular}

Table 5: Stress Testing (forced degradation)

\begin{tabular}{|c|c|}
\hline Degradation factor & Condition \\
\hline Thermal & $\geq 60^{\circ} \mathrm{C}$ \\
\hline Humidity & $\geq 75 \% \mathrm{RH}$ \\
\hline Acid & $\mathbf{0 . 1} \mathbf{N} \mathrm{HCL}$ \\
\hline Base & $\mathbf{0 . 1 \mathrm { N } \mathrm { NaOH }}$ \\
\hline Oxidative & Oxygen gas, 3\% H2O2 \\
\hline Photolytic & Metal halide, $\mathrm{Hg}$, Xe lamp, UV-B fluorescent \\
\hline
\end{tabular}

Types of Stability of drug substance:

\section{Physical Stability:}

The original physical properties, including appearance, palatability, uniformity, dissolution and suspend ability are retained. Physical stability affect to drug uniformity and release rate hence it is important from safety and efficiency point of view.

Chemical Stability:

Each active ingredient retains its chemical integrity and labelled potency within the specified limits. The chemical stability of drug is of great importance since it becomes 
less effective as it undergoes degradation.

Also drug decomposition may yield toxic by-

products that are harmful to the patient.

\section{Microbiological Stability:}

Sterility or resistance to microbial growth is

retained according to the Specified

requirements. Antimicrobial agents retain effectiveness within specified limits.

Microbiological instability of a sterile drug

product could be hazardous.

Therapeutic Stability: The therapeutic

effect remains unchanged.

Toxicological Stability: No significant

increase in toxicity occurs [45].

Table 6: Stability indicating method for Vildagliptin

\begin{tabular}{|c|c|c|c|c|c|c|c|c|}
\hline Sr. No. & Drug & Method & $\begin{array}{l}\text { Column/ } \\
\text { Stationary } \\
\text { Phase }\end{array}$ & $\begin{array}{c}\text { Mobile } \\
\text { Phase \& Chamber } \\
\text { saturation time }\end{array}$ & $\begin{array}{c}\text { Flow Rate, } \\
\text { R.T\&R.T of } \\
\text { Degradation } \\
\text { Product/Develo pment } \\
\text { Time Rf value of drug }\end{array}$ & $\begin{array}{l}\text { Wavelength, } \\
\text { Linearity, } \\
\text { Coefficient } \\
\text { Correlation }\end{array}$ & $\begin{array}{c}\text { LOD \& } \\
\text { LOQ } \\
(\mu \mathrm{g} / \mathrm{mL})\end{array}$ & Ref no. \\
\hline 1. & $\begin{array}{l}\text { Vildaglipti n } \\
\text { Tablet, } \\
\text { Bulk }\end{array}$ & $\begin{array}{c}\text { RP- } \\
\text { HPLC }\end{array}$ & 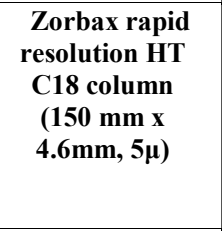 & $\begin{array}{c}\text { Sodium } \\
\text { dihydrogen } \\
\text { phosphate } \\
\text { buffer (pH 6.5) } \\
: \\
\text { Acetonitrile } \\
(50: 50 v / v)\end{array}$ & $\begin{array}{c}\text { Flow rate } 1 \mathrm{ml} / \mathrm{min} \\
\text { Run time }-10 \\
\text { min } \\
\text { Retention time- } 5.017 \mathrm{~min}\end{array}$ & $\begin{array}{l}\text { UV detection } \\
-220 \mathrm{~nm} \\
\text { Linearity - } \\
1060 \mu \mathrm{g} / \mathrm{ml} \\
\mathrm{R} 2-0.9996 \\
\end{array}$ & $\begin{array}{c}\text { LOD - } \\
0.025 \mu \mathrm{g} / \\
\mathrm{ml} \\
\\
\text { LOQ - } \\
0.054 \mu \mathrm{g} / \\
\mathrm{ml}\end{array}$ & [46] \\
\hline 2. & $\begin{array}{c}\text { Vildaglipti n } \\
\text { Tablet }\end{array}$ & RP-LC & $\begin{array}{c}\text { XBridge } \\
\text { analytical } \\
\text { column C8 (150 } \\
\times 4.6 \\
\text { mm i.d., } 5 \\
\mu \mathrm{m} \\
\end{array}$ & $\begin{array}{c}\text { Acetonitrile : } \\
0.3 \% \text { Triethyl } \\
\text { amine pH } 7.0 \\
\text { adjust with } \\
\text { phosphoric acid } \\
(15: 85 \mathrm{v} / \mathrm{v}) \\
\end{array}$ & $\begin{array}{c}\text { Flow rate }-1.0 \\
\mathrm{ml} / \mathrm{min}\end{array}$ & $\begin{array}{c}\text { Photodiode array } \\
\text { (PDA) } \\
\text { detection -207 nm } \\
\text { Linearity -20- } \\
80 \mu \mathrm{g} / \mathrm{ml} \\
\text { R2 - 0.9999 }\end{array}$ & $\begin{array}{c}\text { LOD - } \\
0.63 \mu \mathrm{g} / \mathrm{ml} \\
\text { LOQ - } \\
2.82 \mu \mathrm{g} / \mathrm{ml}\end{array}$ & [47] \\
\hline 3. & $\begin{array}{c}\text { Metformin } \\
\& \\
\text { Vildaglipti n } \\
\text { tablet }\end{array}$ & $\begin{array}{c}\text { RP- } \\
\text { HPLC }\end{array}$ & $\begin{array}{c}\text { Grace Cyano } \\
\text { column } \\
(250 \mathrm{~mm} \times 4 \\
.6 \mathrm{~mm}) \\
5 \mu \mathrm{m}\end{array}$ & $\begin{array}{c}25 \mathrm{~mm} \\
\text { Ammonium } \\
\text { Bicarbonate buffer } \\
(\mathrm{pH} 7): \text { Acetonitrile } \\
(65: 35 \mathrm{v} / \mathrm{v})\end{array}$ & $\begin{array}{c}\text { Flow rate - } \\
1.0 \mathrm{ml} / \mathrm{min} \\
\text { Retention Time } \\
- \\
\underline{\text { MET }}-7.5 \mathrm{~min} \\
\underline{\text { LLG }}-5.3 \mathrm{~min}\end{array}$ & $\begin{array}{l}\text { UV detection- } 207 \\
\text { nm MET: } \\
\text { Linearity -25- } \\
125 \mu \mathrm{g} / \mathrm{ml} \text { VLG : } \\
\text { Linearity -50- } \\
250 \mu \mathrm{g} / \mathrm{ml}\end{array}$ & $\begin{array}{c}\text { MET : } \\
\text { LOD - } \\
0.36 \mu \mathrm{g} / \mathrm{ml} \\
\text { LOQ-1.22 } \\
\mu \mathrm{g} / \mathrm{ml} \text { VLG : } \\
\text { LOD - } \\
0.75 \mu \mathrm{g} / \mathrm{ml} \\
\mathrm{LOQ}- \\
2.51 \mu \mathrm{g} / \mathrm{ml}\end{array}$ & {$[48]$} \\
\hline \multirow[t]{2}{*}{4.} & $\begin{array}{c}\text { Metformin } \\
\& \\
\text { Vildaglipti n } \\
\text { tablet }\end{array}$ & $\begin{array}{c}\text { RP- } \\
\text { HPLC }\end{array}$ & $\begin{array}{c}\text { Thermo hypersil } \\
\text { ODS C18 column } \\
(250 \mathrm{~mm} \times 4 \\
.6 \mathrm{~mm}, 5 \mu \mathrm{m})\end{array}$ & $\begin{array}{c}\text { Methanol : } \\
\text { Acetonitrile: } \\
\text { Phosphate buffer } \\
\text { pH 3.5(5:30:65v/ } \\
\text { v) }\end{array}$ & $\begin{array}{c}\text { Flow rate - } \\
0.8 \mathrm{ml} / \mathrm{min} \\
\text { Retention Time } \\
- \\
\underline{\text { MET }} \mathbf{- 3 . 3 6} \mathrm{min} \\
\underline{\text { VLG }}-\mathbf{5 . 4 1 \mathrm { min }}\end{array}$ & $\begin{array}{l}\text { UV detection- } \\
\text { 212nm MET: } \\
\text { Linearity -10- } \\
140 \mu \mathrm{g} / \mathrm{ml} \text { R2- } \\
0.9917 \text { VLG : }\end{array}$ & $\begin{array}{l}\text { MET: } \\
\text { LOD - } \\
2.18 \\
\mu \mathrm{g} / \mathrm{ml} \mathrm{LOQ-} \\
6.55 \mu \mathrm{g} / \mathrm{ml} \\
\text { VLG : }\end{array}$ & [49] \\
\hline & & & & & Run time $-7 \mathrm{~min}$ & $\begin{array}{c}\text { Linearity }-114 \mu \mathrm{g} / \mathrm{ml} \\
\mathbf{R}^{2}-0.9903\end{array}$ & $\begin{array}{c}\text { LOD - } \\
0.13 \mu g / m l \\
\text { LOQ - } \\
0.38 \mu g / m l\end{array}$ & \\
\hline 5. & $\begin{array}{l}\text { Vildaglipti n } \\
\text { tablet, Bulk. }\end{array}$ & $\begin{array}{c}\text { RP- } \\
\text { HPLC }\end{array}$ & $\begin{array}{c}\text { Jasco crestpack } \\
\text { RP C18 } \\
(250 \mathrm{~mm} x \\
4.6 \mathrm{~mm}, 5 \mu)\end{array}$ & $\begin{array}{c}\text { 0.01M } \\
\text { Disodium Hydrogen } \\
\text { phosphate buffer } \\
\text { pH 6: Acetonitrile: } \\
\text { Methanol } \\
(70: 10: 20)\end{array}$ & $\begin{array}{c}\text { Flow Rate- } \\
1 \mathrm{ml} / \mathrm{min}\end{array}$ & $\begin{array}{c}\text { PDA } \\
\text { Detection- } \\
210 \mathrm{~nm} \\
\text { Linearity - 515 } \mu \mathrm{g} / \mathrm{ml} \\
\mathbf{R}^{2}-0.9999\end{array}$ & $\begin{array}{c}\text { LOD - 200ng/ml } \\
\text { LOQ - } \\
600 \mathrm{ng} / \mathrm{ml}\end{array}$ & [50] \\
\hline 6. & $\begin{array}{c}\text { Vildaglipti n } \\
\text { tablet }\end{array}$ & HPLC MS & $\begin{array}{l}\text { RP C18 column } \\
(250 \times 4.6 \mathrm{~mm}, 5- \\
\text { Hypersil Gold })\end{array}$ & $\begin{array}{c}\text { Acetonitrile } \\
\text { Water (40:60) pH } \\
\text { adjusted at } 7.0 \\
\text { using } \\
\text { triethylamine }\end{array}$ & $\begin{array}{c}\text { Flow Rate- } \\
1 \mathrm{ml} / \mathrm{min}\end{array}$ & $\begin{array}{c}\text { Linearity - 2-12 } \\
\text { ug/ml } \\
\mathbf{R}^{2}=0.9999\end{array}$ & $\begin{array}{c}\text { LOD - } \\
3.61 \mu \mathrm{g} / \mathrm{ml} \\
\mathrm{LOQ}- \\
10.96 \mu \mathrm{g} / \mathrm{ml}\end{array}$ & [51] \\
\hline
\end{tabular}




\section{Bio-Analytical Method :}

These bioanalytical validation technique established by Karnes et al. in 1991which was intentional to give direction to bioanalytical chemists. After one year, Shah et al. established these report the convention on analytical technique validation of bioavailability, bioequivalence and pharmacokinetic studies organized in Washington in 1990 [52].
Bio-analytical method promotes the quantitative analytical technique appropriate biochemical approach. HPLC, RP-HPLC, HPLC-MS/ESI, UPLC-MS, UPLC-TMS, LC and $\mathrm{GC}$ combined with mass spectroscopic procedure, LC-MS, LC-MS/MS. Bioanalysis is innovative technique for improve the accuracy, precision, efficiency, sensitivity, specificity, assays, data handling, processes, analysis cost, data quality [53].

Table 7: Bio-analytical method for Vildagliptin

\begin{tabular}{|c|c|c|c|c|c|c|c|c|c|}
\hline $\begin{array}{l}\text { Sr. } \\
\text { No. }\end{array}$ & Drug & $\begin{array}{c}\text { Metho } \\
\text { d }\end{array}$ & $\begin{array}{l}\text { Bio- } \\
\text { fluid }\end{array}$ & Column & Mobile phase & $\begin{array}{l}\text { Flow rate } \\
\& \\
\text { retention } \\
\text { time }\end{array}$ & $\begin{array}{l}\text { Detection } \\
\text { /Detector }\end{array}$ & $\begin{array}{l}\text { Linearity, } \\
\text { LOD, } \\
\text { LOQ }\end{array}$ & Ref. No. \\
\hline 1 & $\begin{array}{c}\text { Vildagliptin and } \\
\text { Telmisartan }\end{array}$ & RP HPLC & $\begin{array}{l}\text { Rabbit } \\
\text { plasma }\end{array}$ & $\begin{array}{c}\text { Kromasil } \\
\text { C18 } \\
\text { Column } \\
(100 m m \\
x\end{array}$ & $\begin{array}{c}\text { Acetonitrile: } \\
\text { Methanol } \\
(75: 25 v / v)\end{array}$ & $\begin{array}{c}\text { Flow } \\
\text { Rate1ml/min } \\
\text { Retention }\end{array}$ & $\begin{array}{c}\text { PDA } \\
\text { Detector at } \\
225 \mathrm{~nm}\end{array}$ & $\begin{array}{c}\text { VLG: } \\
\text { Linearity - } \\
24.979- \\
5003.838 \mu \mathrm{g} \\
\quad / \mathrm{ml}\end{array}$ & 54] \\
\hline
\end{tabular}

\begin{tabular}{|c|c|c|c|c|c|c|c|c|c|}
\hline & & & & $\begin{array}{c}4.6 \mathrm{~mm} \text {, } \\
5 \mu)\end{array}$ & & $\begin{array}{l}\text { Time : } \\
\text { VLG- } \\
2.5 \mathrm{~min} \\
\text { TMS- } \\
6.6 \mathrm{~min}\end{array}$ & & $\begin{array}{c}\text { TMS: } \\
\text { Linearity- } \\
1.011- \\
202.55938 \mu \mathrm{g} / \mathrm{ml}\end{array}$ & \\
\hline 2. & $\begin{array}{c}\text { Metformin } \\
\& \\
\text { Vildagliptin } \\
\text { tablet }\end{array}$ & $\begin{array}{c}\text { RP- } \\
\text { HPLC }\end{array}$ & $\begin{array}{l}\text { Huma } \\
\text { n } \\
\text { Plasm } \\
\text { a }\end{array}$ & $\begin{array}{c}\text { Thermo } \\
\text { hypersil } \\
\text { ODS C18 } \\
\text { column } \\
(250 \mathrm{~mm} \\
\times 4.6 \mathrm{~mm} \\
, 5 \mu \mathrm{m})\end{array}$ & $\begin{array}{c}\text { Methanol : } \\
\text { Acetonitrile: } \\
\text { Phosphate } \\
\text { buffer pH } \\
\text { 3.5(5:30:65 v/v) }\end{array}$ & 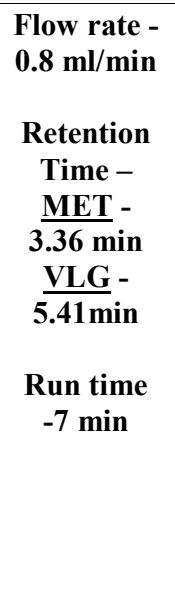 & $\begin{array}{c}\text { UV } \\
\text { detection- } \\
212 \mathrm{~nm}\end{array}$ & $\begin{array}{c}\text { MET: } \\
\text { Linearity - } \\
\mathbf{1 0 -} \\
\mathbf{1 4 0} \boldsymbol{\mu g} / \mathbf{m l} \\
\mathbf{R}^{2}-\mathbf{0 . 9 9 1 7} \\
\text { LOD -2.19 } \\
\mu \mathrm{g} / \mathrm{ml} \\
\text { LOQ-6.57 } \\
\mu \mathrm{g} / \mathrm{ml} \\
\text { VLG : } \\
\text { Linearity-1 } \\
14 \mu \mathrm{g} / \mathrm{ml} \\
\mathbf{R}^{2} \mathbf{- 0 . 9 9 0 3} \\
\text { LOD - } 0.14 \\
\boldsymbol{\mu g} / \mathbf{m l ~ L O Q ~ - ~} \\
\mathbf{0 . 4 1} \boldsymbol{\mu g} / \mathbf{m l}\end{array}$ & [49] \\
\hline 3. & $\begin{array}{c}\text { Vildagliptin } \\
\text { tablet }\end{array}$ & $\begin{array}{c}\text { LCMS/M } \\
\mathrm{S}\end{array}$ & $\begin{array}{l}\text { Rat } \\
\text { Plasm } \\
\text { a }\end{array}$ & $\begin{array}{c}\text { Betasil C18 } \\
\text { column } \\
(50 \mathrm{~mm} \times \\
4.6 \mathrm{~mm},\end{array}$ & $\begin{array}{c}\text { Acetonitrile: } \\
2 \mathrm{mM} \\
\text { Ammonium } \\
\text { acetate pH3.4 }\end{array}$ & $\begin{array}{c}\text { Flow rate - } \\
0.35 \mathrm{ml} / \mathrm{min} \\
\text { Retention } \\
\text { Time - }\end{array}$ & $\begin{array}{l}\text { API } 3200 \text { Q } \\
\text { trap triple } \\
\text { quadrupole } \\
\text { (TMS) via }\end{array}$ & $\begin{array}{c}\text { VLG : } \\
\text { Linearity- } \\
1.57501 .21 \mathrm{ng} / \mathrm{ml} \\
\mathrm{R}^{2} \geq 0.99\end{array}$ & [55] \\
\hline
\end{tabular}




\begin{tabular}{|c|c|c|c|c|c|c|c|c|c|}
\hline & & & & $5 \mu \mathrm{m}$ & $(90: 10 v / v)$ & $\begin{array}{c}1.68 \mathrm{~min} \\
\text { Run time } \\
-3 \mathrm{~min}\end{array}$ & $\begin{array}{c}\text { Electrospray } \\
\text { Ionization } \\
\text { Source } \\
\end{array}$ & $\begin{array}{c}\text { LOQ- } \\
1.57 \mathrm{ng} / \mathrm{ml}\end{array}$ & \\
\hline 4. & $\begin{array}{c}\text { Vildagliptin } \\
\text { tablet }\end{array}$ & $\begin{array}{c}\text { RP- } \\
\text { HPLC }\end{array}$ & $\begin{array}{c}\text { Huma } \\
\text { n } \\
\text { Plasm } \\
\text { a }\end{array}$ & $\begin{array}{c}\text { XBridge } \\
\text { Shield C18 } \\
\text { column } \\
(150 \mathrm{~mm} \\
\times 4.6 \mathrm{~mm} \\
, 3.5 \mu \mathrm{m}) \\
\end{array}$ & $\begin{array}{c}\text { 50Mm } \\
\text { Ammonium } \\
\text { bicarbonate } \\
\text { pH7.8 : } \\
\text { Acetonitrile }\end{array}$ & $\begin{array}{c}\text { Flow rate } \\
-1 \mathrm{ml} / \mathrm{min} \\
\\
\text { Retention } \\
\text { Time - } \\
\text { 11.2 min } \\
\end{array}$ & $\begin{array}{c}\text { UV } \\
\text { detection- } \\
210 \mathrm{~nm}\end{array}$ & $\begin{array}{c}\text { Linearity- 10- } \\
120 \mu \mathrm{g} / \mathrm{ml}\end{array}$ & {$[56]$} \\
\hline 5. & $\begin{array}{c}\text { Vildagliptin } \\
\text { tablet }\end{array}$ & $\begin{array}{c}\mathrm{LCMS} / \mathrm{M} \\
\mathrm{S}\end{array}$ & $\begin{array}{l}\text { Rat } \\
\text { Plasm } \\
\text { a }\end{array}$ & $\begin{array}{c}\text { ACE3 } \\
\text { C18 PEP } \\
\text { Column } \\
(150 \mathrm{~mm} \\
\times 4.6 \mathrm{~mm} \\
, 3 \mu \mathrm{m})\end{array}$ & $\begin{array}{c}10 \mathrm{mM} \\
\text { Ammonium } \\
\text { acetate buffer } \\
\text { :Acetonitrile } \\
(20: 80 \mathrm{v} / \mathrm{v})\end{array}$ & $\begin{array}{c}\text { Flow rate - } \\
\mathbf{0 . 7} \mathrm{ml} / \mathrm{min} \\
\\
\text { Retention } \\
\text { Time - } \\
\text { 3-3.20 } \\
\text { Min }\end{array}$ & $\begin{array}{l}\text { Ionized in the } \\
\text { positive } \\
\text { Electrospray } \\
\text { ionization ion } \\
\text { source of mass } \\
\text { spectrometer }\end{array}$ & $\begin{array}{c}\text { Linearity- } \\
7.063023 .81 \\
\mathrm{ng} / \mathrm{ml}^{2}>0.99 \\
\text { LOQ - } \\
7.06 \mathrm{ng} / \mathrm{ml}\end{array}$ & [57] \\
\hline
\end{tabular}

\section{CONCLUSION}

The present review illustrates various analytical approaches exercised for the estimation of Vildagliptin. A numerous investigation had perform including, Bioanalytical, Stability Indicating, HPLC, UVVisible Spectroscopy and LC-MS, etc. for estimation of Vildagliptin in bulk and in its combined pharmaceutical formulations and in plasma. Reverse Phase Liquid Chromatography with UV detection has been found to be most studied for estimation of Vildagliptin. In bulk as well as pharmaceutical dosage forms, while hyphenated such as LC-MS methods are reported for determination of Vildagliptin and its metabolite in plasma and other biological fluids. Few chromatography approaches like UHPLC and UV Spectrophotometry methods are also used for assay of Vildagliptin.

\section{REFERENCES}

[1] Ahmed AM. History of diabetes mellitus. Saudi Med J 2002. Apr;23(4):373-378 [PubMed][Google Scholar]

[2] Diabetes mellitus history- from ancient to modern times. Available athttp://science.jrank.org/pages/2044/D iabetes-Mellitus.html(accessed on 22nd July, 2011)

[3] Patlak M. New weapons to combat an ancient disease: treating diabetes. FASEB J 2002. Dec;16(14):1853 10.1096/fj.02-0974bkt [PubMed] [CrossRef][Google Scholar]

[4] Maitra A, Abbas AK. Endocrine system. In: Kumar V, Fausto N, Abbas AK (eds). Robbins and Cotran Pathologic basis of disease (7th ed) 2005. Philadelphia, Saunders; 11561226. [Google Scholar] 
[5] Chen L, Magliano DJ, Zimmet PZ. The worldwide epidemiology of type 2 diabetes mellitus: present and future perspectives. Nature reviews endocrinology. Available at:www.nature.com/uidfinder(Accessed 22nd December 2011) [PubMed]

[6] Hussain S, Chowdhury TA. The Impact of Comorbidities on the Pharmacological Management of Type 2 Diabetes Mellitus. Drugs. 2019 Feb;79(3):231-242. [PubMed]

[7] Rajeev Goyal; Ishwarlal Jialal. Diabetes Mellitus Type 2. Stat Pearls Publishing; 2021 Jan.

[8] https://en.m.wikipedia.org /wiki/vildagliptin.

[9] Somasekhar V, Gowrisankar D, Shivakumar HN. Developement and validation of rapid RPHPLC method for the determination of venlafaxine hydrochloride in pharmaceutical dosage forms using experimental design. Journal of chemistry.2009;6(4):1091-102.

[10] https://pubchem.ncbi.nlm.nih.gov.

[11] Yadav Vidushi, Bharkatiya Meenakshi. A review on hplc method development and validation.Life science informatics publications, RJLBPCS 2017.
[12] Vijendra H. Rajan, Development and validation of hplc method a review, international journal of current research in pharmacy 2015; volume1(2): 55-68.

[13] Malakar, A., Bokshi, B., \& Nasrin, D. (2012). Development and validation of RP-HPLC method for estimation of Vildagliptin from table dosage form. International Journal of Pharmaceutical and Life Sciences, 1(1).

[14]B.Santhosha, A.Ravindranath , Ch.Sundari .Validated method for the simultaneous estimation of Metformin Hydrochloride and Vildagliptin by RPHPLC in bulk and the pharmaceutical dosage form.Int. Res J Pharm. App Sci., 2012; 2(3):22-28.

[15]K. Manohar, B. Thangabalan, S. Manohar Babu. Method Development and validation for the simultaneous estimation of Vildagliptin and metformin in tablet dosage form by RP-HPLC. International Journal of Research in Pharmaceutical and Nano sciences.3(2),2014,80-87.

[16] Jagdale R.R .,Dabhade M.P., Kokate S.V.,ShindeV.S.,Shaikh W.C., RPHPLC method Development and validation of Vildagliptin in bulk and dosage form.World Journal of 
pharmacy and pharmaceutical sciences, Volume 6,Issue 9,1161-1176.

[17] W. Abu Dayyih , M. Hamad , E. Mallah, A. Abu Dayyih, R. Awad, Z. Zakaria and T. Arafat. Method Development And Validation Of Vildagliptin And Metformin $\mathrm{HCl}$. In Pharmaceutical Dosage Form by Reverse Phase-High Performance Liquid Chromatography (RP-Hplc). IJPSR, 2018; Vol. 9(7): 2965-2972.

[18]D Raju, P Karunakar, China Babu Jonnakuti and N Asha .,Simultaneous estimation of vildagliptin and metformin hydrochloride by using RPHPLC in bulk and pharmaceutical dosage form.,The Pharma Innovation Journal 2019; 8(6): 296-301.

[19] Sagar Kishor Savale., Development and Validation of RP-HPLC Method for Estimation of Vildagliptin. Asian Journal of Biomaterial Research 2017; 3(5):6-11.

[20] Gattu Madhava Prathap, Muthukumaran M, Krishnamoorthy B.Development and Validation of Simultaneous Estimation of Vildagliptin \& Metformin Hydrochloride by RP-HPLC in Bulk and Oral Dosage Form.Int J Adv Pharm Gen Res, 2(1), 2014; 24-33.
[21]B. Mohammed Ishaq, Dr. K. Vanitha Prakash, Dr. G. Krishna Mohan. RPHplc Method For Simultaneous Estimation Of Metformin And Vildagliptin In Bulk And Its Tablet Formulation.Journal of Global Trends in Pharmaceutical Sciences Vol.3, Issue 3, pp. -747-754, July- September 2012.

[22] Baokar S.B.,Mulgund S.V.,Ranpise N.S., Development and Validation of RP-HPLC method for Simultaneous Estimation of Vildagliptin \& Metformin. Research journal of pharmaceutical dosage forms and technology.year:2013, Volume: 5, Issue: 2, page 95-98.

[23] Sultana, S., Kumar, U., Hossain, M. S., Lira, D. N., \& Rouf, A. S. S. (2017). QbD Approach for the Development and Validation of RP-UHPLC Method for Quantitation of Vildagliptin. Dhaka University Journal of Pharmaceutical Sciences, 16(1), 107-117.

[24] Nandipati, S., v, K. R., \& T, R. R. (2012). Development and Validation of RP-HPLC method for Simultaneous Determination of Vildagliptin and Metformin in Bulk and Formulation Dosage. International Research Journal 
of Pharmaceutical and Applied

Sciences, 2(3), 44-50.

[25] Thangabalan

Boovizhikannan,

Vijayaraj Kumar Palanirajan. RPHPLC determination of vildagliptin in pure and in tablet formulation. Journal of Pharmacy Research Volume 7, Issue 1, January 2013, Pages 113-116.

[26] Pragati Ranjan Satpathy, V. Mohan Goud, Bhoga Bhagya, Jvc. Sharma \& N.Shyamala. Development and validation of a RP-HPLC method for the assay of vildagliptin. World Journal of Pharmacy and Pharmaceutical sciences. Volume 3, Issue 2, 23032310.

[27]Rao, K. Hanumantha; Rao, A. Lakshmana; Sekhar, K. B. Chandra . Development and Validation of Hplc Method for the Estimation of Vildagliptin In Pharmaceutical Dosage Form. International Journal of Pharmaceutical, Chemical \& Biological Sciences . Apr-Jun2014, Vol. 4 Issue 2, p361-366. 6p.

[28] Khatun, R., \& Mirazzunnabi, M. (2013). A Validated Reversed-Phase HPLC Method for the Determination of Vildagliptin from Tablet Dosage Form. International Journal of Pharmaceutical and Life Sciences, 2(3), 90-98.
[29] Viralkumar Patel, Chintan Pandya, Aditee Pandya, Dharmesh Patel, Zalak Patel Novel UHPLC DAD Method for Simultaneous determination of Vildagliptin and Metformin in Bulkand its Tablet formulation.

[30] A.R.Shirode, P.D.Maduska, M.S.Deodhar, V. J. Kadam. RP-HPLC and HPTLC Methods for Simultaneous Estimation of Metformin Hydrochloride and Vildagliptin from Bulk and Marketed Formulation: Development and validation. British Journal of Pharmaceutical Research 4(20):2370-2386, 2014.

[31]V. Nagalakshmi, G. Srinivas Rao, N. Gayathri Devi, S. Mohan. RP-HPLC Method for Simultaneous Estimation of Vildagliptin and Metformin in Bulk and Pharmaceutical Formulations. International Journal of Current Research and Review .Vol 13 Issue 07 April 2021.

[32] Chatwal G.R., Anand S.K. Instrumental Methods of Chemical Analysis. Himalaya publishing House. $5^{\text {th }}$ edition 2006.

[33]Dr. Safila Naveed, Hina Rehman, Fatima Qamar and Syeda Zainab. Method development and validation of Vildagliptin using UV 
spectrophotometer. International

Journal of Pharma Sciences and Research (IJPSR) Vol 5 No 10 Oct 2014 ISSN : 0975-949.

[34] Samer Housheh, Hanan Mohammad, Youssef Alahmad. Spectrophotometric Method for the Determination of Vildagliptin in Bulk and Pharmaceutical Dosage Forms. Int. J. Pharm. Sci. Rev. Res., 58(2), September - October 2019; Article No. 17, Pages: 117-120 ISSN 0976 - 044X. [35] Usharani Gundala , Chandra Shekar Bhuvanagiri, Devanna Nayakanti. Simultaneous Estimation of Vildagliptin and Metformin in Bulk and Pharmaceutical Formulations by UV Spectrophotometry. Am. J. PharmTech Res. 2013; 3(1) ISSN: 2249-3387.

[36] Beena Kumari ,Aparna Khansili . Analytical Method Development and Validation of UVvisible Spectrophotometric Method for the Estimation of Vildagliptin in Gastric Medium. Drug Research (Stuttg) 2020; 70(09): 417-423.

[37]P.V. Prasad, K. Divya, M.V. Ramana, A. Krishnaveni, J. Vinay, M. Mahadeswar. Analytical Method Development and Validation for the
Estimation of Vildagliptin in bulk and its dosage form using UV-visible Spectrophotometer. Indo American Journal of Pharmaceutical Research. 2017: 7(12).

[38]Banik, S., Karmakar, P., \& Miah, M. A. H. (2015). Development and Validation of a UVSpectrophotometric Method for Determination of Vildagliptin and Linagliptin in Bulk and Pharmaceutical Dosage Forms. Bangladesh Pharmaceutical Journal, 18(2), 163-168.

[39] Baokar Shrikrishna, Mulgund S. V. and Ranpise N. S. Simultaneous spectrophotometric estimation of vildagliptin and metformin in bulk and tablet dosage form. Der Pharma Chemica, 2013, 5(1):24-27.

[40] Bakshi M., Singh S. Development of validated stability-indicating assay methods-critical review. Journal of Pharmaceutical and Biomedical Analysis. 2002;28(6):1011-1040.

[41] Singh S., Bakshi M. Guidance on Conduct of Stress Testing to Determine Inherent Stability of Drugs. Pharmaceutical Technology; 2000.

[42] Sonawane S., Gide P. Application of experimental design for the optimization of forced degradation and 
development of a validated stability indicating LC method for luliconazole in bulk and cream formulation. Arabian Journal of Chemistry. 2012

[43] https://www.ambiopharm.com

[44]Blessy MR,Patel RD,Prajapati PN,Agarwal YK.Development of forced degradation and stability indicating studies of drugs - A review.Journal of pharmaceutical analysis.2014 Jun1; 4(3): 159-65.

[45] Suthar Narayan, Choudhary Manupriya ; a review on stability studies of pharmaceutical products ISSN : 24560189; International journal of Applied Pharmaceutical and Biological Research, 2017; 2(3): 67-75.

[46] Razia Sultana, Sitesh C. Bachar and Fatema Rahman. Development and validation of stability indicating assay method of vildagliptin in bulk and tablet dosage form by RP-HPLC. Int. J. of Pharm. \& Life Sci. (IJPLS), Vol. 4, Issue 4: April: 2013, 2530-2534 2530.

[47] Amanda Thomas Barden, Bárbara Salamon, Elfrides Eva Sherman Schapoval, Martin Steppe, StabilityIndicating RP-LC Method for the Determination of Vildagliptin and Mass Spectrometry Detection for a Main Degradation Product, Journal of
Chromatographic Science, Volume 50, Issue 5, May 2012, Pages 426-432.

[48] Satheeshkumar, N., Pradeepkumar, M., Shanthikumar, S., \& Rao, V. J. (2014). Development of validated stability indicating assay method for simultaneous estimation of metformin hydrochloride and vildagliptin by RPHPLC. Drug research, 64(03), 124-129. [49] Shakoor, A., Ahmed, M., Ikram, R., Hussain, S., Tahir, A., Jan, B. M., \& Adnan, A. (2020). Stability-indicating RP-HPLC method for simultaneous determination of metformin hydrochloride and vildagliptin in tablet and biological samples. Acta Chromatographica, 32(1), 39-43.

[50] Chaphekar, Meetali M., and Purnima D. Hamrapurkar. "Development and validation of RPHPLC assay method for vildagliptin using QbD approach and its application to forced degradation studies." International Journal of Pharmaceutical Sciences and Drug Research 8.3 (2016): 157-165.

[51]Dhale, C., and J. R. Rao. "Stability Indicating HPLC MS Method for Determination of Degradation Products in Vildagliptin." J Anal Bioanal Tech 10.420 (2019): 2. Volume 10 Issue 2 1000420 
[52] Tiwari G, Tiwari R.Bioanalytical method validation: An updated review. Pharmaceutical methods .2010 Oct $1 ; 1(1): 25-38$.

[53] Shah VP, Midha KK, Findlay JW, Hill HM, Hulse JD, McGilveray IJ, McKay G,Miller KJ, Patnaik RN, Powell ML,Tonelli A. Bioanalytical method validation - a revisit with a decade of progress .Pharmaceutical research .2000 Dec 1;17(12):1551-7.

[54]Reddy, Budideti Kishore Kumar, Kothapalli Bonnoth Chandra Sekhar, and Chinnala Krishna Mohan. "Bioanalytical Method Development and Validation for the Simultaneous Determination of Vildagliptin and Telmisartan in Rabbit Plasma Using RP-HPLC." Journal of Pharmaceutical Research International (2021): 76-86.

[55] Sakthimanigandan, K., Ganesh, M., Kanthikiran, V., Sivakumar, T., \& Jang, H. (2015). Liquid chromatography tandem mass spectrometry (LC-MS/MS) method for the determination of Vildagliptin in rat plasma. Acta Chromatographica, 27(2), 295-307.

[56] Pharne, A. B., Santhakumari, B., Ghemud, A. S., Jain, H. K., \& Kulkarni, M. J. (2012). Bioanalytical method development and validation of vildagliptin a novel dipeptidyl peptidase IV inhibitor by RP-HPLC method. International Journal of Pharmacy and Pharmaceutical Sciences, 4(3), 119-23.

[57] Tiwari, A., Sethi, V. A., Siddiqui, A. W., Panigrahy, B. K., Khuroo, A. H., \& Tyagi, L. K. (2019). Bioanalytical method development and validation of vildagliptin in rat plasma using LCMS/MS method. Journal of Advanced Scientific Research, 10(3): 22-29. 